\title{
Postpartum assessment of fetal inflammatory response syndrome in a preterm population with premature rupture of membranes: A Romanian study
}

\author{
GABRIELA CORINA ZAHARIE ${ }^{1}$, TUDOR DRUGAN ${ }^{2 *}$, CARMEN CRIVII $^{3 *}$, DANIEL MURESAN $^{4 *}$, \\ ALEXANDRU ZAHARIE ${ }^{5 *}$, MONICA GABRIELA HĂȘMĂȘANU ${ }^{1}$, FLAVIU ZAHARIE ${ }^{6}$ and MELINDA MATYAS ${ }^{1}$ \\ Departments of ${ }^{1}$ Neonatology, ${ }^{2}$ Anatomy and Embryology, ${ }^{3}$ Medical Informatics and Biostatistics, and \\ ${ }^{4}$ Obstetrics and Gynecology I, 'Iuliu Haţieganu' University of Medicine and Pharmacy, 400012 Cluj-Napoca, Romania; \\ ${ }^{5}$ Department of Radiation Oncology, Medical University of Vienna, 1090 Vienna, Austria; \\ 6،Iuliu Haţieganu' University of Medicine and Pharmacy, 400012 Cluj-Napoca, Romania
}

Received August 6, 2021; Accepted September 7, 2021

DOI: $10.3892 / \mathrm{etm} .2021 .10862$

\begin{abstract}
Fetal inflammatory response syndrome is associated with increased neonatal morbidity and mortality. The aim of the present study was to evaluate the dynamics of the plasmatic value of pro-inflammatory cytokines: tumor necrosis factor- $\alpha$ (TNF- $\alpha$ ), interleukin-6 (IL-6) and neutrophil activating peptide 78 (ENA-78) and the anti-inflammatory cytokine IL-10 in the first and third day of life and the correlation with neonatal morbidities and mortality. The current research was designed as a prospective case control study included 80 neonates hospitalized at the 3rd level Neonatal Intensive Care Unit (NICU), 1st Gynecology Clinic, County Emergency Hospital, Cluj-Napoca, Romania. For each patient, the following parameters were noted: $\mathrm{pH}$ at first hour of life, oxygen saturation, fraction of inspired oxygen $\left(\mathrm{FiO}_{2}\right)$ and duration of premature rupture of the membranes (PROM). Measurements of cytokines were determined from venous blood in the first and third day of life. The values of all cytokines were higher in the newborns from mothers with PROM.
\end{abstract}

Correspondence to: Dr Monica Gabriela Hăşmășanu, Department of Neonatology, 'Iuliu Haţieganu' University of Medicine and Pharmacy, 8 Babeş Street, 400012 Cluj-Napoca, Romania

E-mail: monica.hasmasanu@gmail.com

*Contributed equally

Abbreviations: IL-6, interleukin-6; ENA-78, epithelial cell-derived neutrophil activating peptide 78 ; TNF- $\alpha$, tumor necrosis factor- $\alpha$; IL-10, interleukin-10; CRP, C-reactive protein; PROM, premature rupture of the membranes; $\mathrm{FiO}_{2}$, fraction of inspired oxygen; $\mathrm{HC}$, head circumference; L, length; RDS, respiratory distress syndrome; NEC, necrotizing enterocolitis; NICU, Neonatal Intensive Care Unit; FIRS, fetal inflammatory response syndrome

Key words: newborn, IL-6, ENA-78, TNF- $\alpha$, IL-10, PROM, perinatal morbidity
The value of IL-6 in the study group was higher compared to the controls during the first day of life and met the highest value in necrotizing enterocolitis (NEC). ENA-78 was higher in the study group $(\mathrm{P}=0.037)$ and decreased during the first 3 days of life. The highest value of ENA-78 was found in the neonates with cerebral hemorrhage. IL-10 also had values with a significant difference in the first day of life between both groups $(\mathrm{P}=0.02)$. IL-10 had the highest value in sepsis cases. In conclusion, among the inflammatory parameters that were evaluated, the dynamics of ENA-78 and IL-10 were found to influence the neonatal prognosis of newborns with PROM. The decrease in ENA-78 and IL-10 during the third day of life could suggest the evolution towards the ending of the inflammatory process and an increase in the survival rate was noted.

\section{Introduction}

Fetal inflammatory response syndrome (FIRS) describes a condition characterized by the presence of a systemic inflammatory response, which is defined by an elevated umbilical cord interleukin (IL)-6 level (1). This phenomenon is associated with increased fetal morbidity and mortality. Most frequently, FIRS occurs as a result of the activation of the innate immune system, due to exposure to microorganisms or other non-infectious stimuli (e.g. alarmins) (1). The immaturity of the immune system together with the intensity of inflammation determines the risk of perinatal complications. The evidence to date suggests that modulating the immune response using antimicrobial agents, anti-inflammatory drugs or cell-based therapy may reduce infant morbidity and mortality. The repercussions of the inflammatory imbalance are either systemic, or confined to an organ, depending on the type of response (1).

The cytokine profile at birth could be indicative of neonatal morbidity in the preterm newborn with premature rupture of membranes (PROM) (2). There are several inflammatory markers involved in FIRS. Epithelial cell-derived neutrophil activator 78 (ENA-78), also known as CXCL-5, is a good example of a chemokine, which has been strongly and consistently correlated with the concentration of recruited 
neutrophils in the lung fluids of newborns with respiratory distress syndrome (RDS) (3). Another example is tissue necrosis factor- $\alpha$ (TNF- $\alpha)$, one of the main mediators of inflammation, mainly involved in lung inflammation (4). Fetal systemic inflammation is causally related with neuro-inflammation, brain injury and or neurodevelopmental disorders (5). Furthermore, IL-8, CXCL-5 and IL-10 levels are elevated in infants with necrotic enterocolitis (NEC) compared to those with sepsis (2). The aim of the present study was firstly to evaluate the dynamics of the plasmatic values of the pro-inflammatory cytokines TNF- $\alpha$, IL- 6 and ENA-78 and the anti-inflammatory cytokine IL-10. The expression levels of these inflammatory markers were evaluated in neonates born from PROM mothers and compared to these levels in neonates born from mothers without PROM. Second, we looked for the possible correlations between the patterns of the parameters studied and their prognostic value regarding survival.

\section{Patients and methods}

Study population. The analyzed population in this prospective study comprised a case group and a control group. Inclusion criteria were preterm newborns under 37 weeks gestational age with and without PROM. Exclusion criteria were as follows: insufficient details in the medical charts of the patients and newborns with genetic disorders.

The study group contained a total of 36 newborns from mothers with PROM. The control group comprised 46 healthy newborns from mothers without PROM. All the neonates were hospitalized at the 3rd level Neonatal Intensive Care Unit (NICU), 1st Gynecology Clinic, County Emergency Hospital Cluj-Napoca, Romania. In obtaining inform consent and conducting the evaluations, the study adhered to principles outlined in the Declaration of Helsinki on experimentation involving human subjects. We obtained the ethics approval of the Ethics Committee County Emergency Hospital Cluj-Napoca, Romania, no. 140/25.06. 2017.

Measurement of the study parameters. We quantified the following parameters: the $\mathrm{pH}$ in the first hour of life, oxygen saturation, fraction of inspired oxygen $\left(\mathrm{FiO}_{2}\right)$ and duration of PROM.

The parameters were registered on the first and third day of life for the study group and on the first day of life for the control group.

Astrup parameters were conducted using a radiometer, ABL90 Flex Blood gas analyzer (Radiometer). All the subjects were monitored using the vital functions monitor, Mindray Patient Monitor, model iPM12 (GE Healthcare), measuring heart rate, $\mathrm{O}_{2}$ saturation, respiratory rate and blood pressure.

Hematological studies were conducted using the Hematology Analyzer 5 diff MS 4S. Melet Schoesing (Biometric Medical Services) from $0.2 \mathrm{ml}$ venous blood.

Measurements of the cytokines [C-reactive protein (CRP), IL-6, ENA-78, IL-10, TNF- $\alpha$ ] were determined from venous blood. Blood levels of the cytokines were measured with a specific ELISA according to the manufacturer's instructions. We used the following kits: RD D6050 Human IL6 Elisa, RD-D1000B Human IL10 Elisa, RD-DTA00C Human TNF- $\alpha$, RD-DX000 CXCL5/ENA-78 (Quantikine ELISA,
R\&D Systems, Inc.) for laboratory analysis. In our study, TECAN Sunrise machine was used.

Assessment of infant morbidity. The morbidity was evaluated using criteria for respiratory distress syndrome (RDS), neonatal sepsis, necrotizing enterocolitis (NEC), cerebral hemorrhage $(\mathrm{CH})$ and mortality.

$R D S$. The Vermont Oxford Network (VON) definition for RDS (6) requires an arterial tension $\mathrm{PaO}_{2}<50 \mathrm{mmHg}$ and central cyanosis in room air, a requirement for supplemental oxygen to maintain $\mathrm{PaO}_{2}>50 \mathrm{mmHg}$ or a requirement for supplemental oxygen to maintain a pulse oximeter saturation $>85 \%$.

Neonatal sepsis. Neonatal sepsis is defined as a systemic condition of bacterial, viral, or fungal (yeast) origin that is associated with hemodynamic changes and other clinical manifestations which results in substantial morbidity and mortality. There are challenges to assessing neonatal sepsis (7). At present, there is no universally accepted definition of neonatal sepsis. The isolation of an infective organism from blood or CSF is one of the commonest criteria in the current literature (7).

NEC. The Centers for Disease Control and Prevention (CDC) surveillance definition for NEC is similar to the VON definition, with some modifications $(6,7)$. Neonates must have at least one of the following clinical findings: bilious aspirate (excluding aspirate obtained from a transpyloric tube), vomiting, abdominal distention, or occult/gross blood in stools (with no rectal fissure). In addition, infants must have at least one of the following imaging findings: pneumatosis intestinalis, portal venous gas (hepatobiliary gas), or pneumoperitoneum. If at least one imaging test finding is equivocal, then clinical correlation with physician documentation of antimicrobial treatment for NEC is needed (8).

Cerebral hemorrhage. Cerebral hemorrhage is defined as hemorrhagic lesion of the central nervous system (CNS) occurring in the fetal, perinatal, or postnatal period (9).

Statistical analysis. The distribution of quantitative variables was assessed with the Shapiro-Wilk test. For the normal distributed variables, means were compared with the Student's t-test. In the event variables did not coincide with a normal distribution, distributed variables were compared with the Mann-Whitney Wilcoxon, Wilcoxon signed rank or Kruskal-Wallis test. For all test we assumed a significance level of 0.05 . Even if not all variables were normally distributed, to maintain a common approach, all values are expressed as means \pm standard deviation (SD). Statistical analysis was conducted with the IBM SPSS v.25 (IBM, Corp).

\section{Results}

Anthropometric data. The anthropometric data of the groups are presented in Table I. The average weight of the neonates in the study group was $2,441.43 \pm 926.97 \mathrm{~g}$ compared with $2,850.00 \pm 948.28 \mathrm{~g}$ in the control group. The gestational age of the study group was $35.71 \pm 3.98$ weeks vs. $36.64 \pm 3.80$ weeks 
Table I. Anthropometric data.

\begin{tabular}{lccr}
\hline & Study group $(\mathrm{n}=36)$ & Control group $(\mathrm{n}=46)$ & P-value \\
\hline Weight $(\mathrm{g})$ & $2,441.43 \pm 926.97$ & $2,850.00 \pm 948.28$ & 0.183 \\
Gestational age (weeks) & $35.71 \pm 3.98$ & $36.64 \pm 3.80$ & 0.459 \\
PROM (h) & $78.40 \pm 139.90$ & $15.00 \pm 2.83$ & $\mathbf{0 . 0 0 1}$ \\
HC (cm) & $32.63 \pm 3.48$ & $35.00 \pm 2.96$ & $\mathbf{0 . 0 3 0}$ \\
L (cm) & $48.63 \pm 6.58$ & $50.50 \pm 5.75$ & 0.357 \\
\hline
\end{tabular}

PRM, premature rupture of the membranes; HC, head circumference; $L$, length. Data are presented as the mean \pm SD. P-values were determined using the Student's t test. Significant $\mathrm{P}$-values $(\mathrm{P}<0.05)$ are indicated in bold print.

Table II. Blood parameters in the study and control group.

\begin{tabular}{|c|c|c|c|}
\hline Blood parameters & Study group $(n=36)$ & Control group $(n=46)$ & P-value \\
\hline pH 1st day & $7.30 \pm 0.087$ & $7.31 \pm 0.042$ & 0.880 \\
\hline $\mathrm{pH} 3$ rd day & $7.32 \pm 0.058$ & $7.34 \pm 0.42$ & 0.497 \\
\hline Paired comparation & 0.001 & 0.517 & \\
\hline Oxygen saturation (\%) 1st day & $81.26 \pm 11.94$ & $89.29 \pm 16.45$ & 0.004 \\
\hline Oxygen saturation (\%) 3rd day & $90.29 \pm 16.45$ & $91.50 \pm 8.89$ & 0.192 \\
\hline Paired comparation & 0.064 & 0.111 & \\
\hline WBC $\left(-/ \mathrm{mm}^{3}\right) 1$ st day & $14,992 \pm 6,398$ & $11,871 \pm 3,875$ & 0.044 \\
\hline WBC $\left(-/ \mathrm{mm}^{3}\right) 3 \mathrm{rd}$ day & $12,701 \pm 3925$ & $13,125 \pm 5,745$ & 0.846 \\
\hline Paired comparation & $<0.001$ & 0.343 & \\
\hline Plaquettes $\left(-/ \mathrm{mm}^{3}\right) 1$ st day & $287,143 \pm 119,407$ & $291,397 \pm 210,563$ & 0.929 \\
\hline Plaquettes $\left(-/ \mathrm{mm}^{3}\right) 3 \mathrm{rd}$ day & $233,608 \pm 72,098$ & $309,750 \pm 92,312$ & 0.059 \\
\hline Paired comparation & 0.010 & 0.264 & \\
\hline $\mathrm{RBC}\left(-/ \mathrm{mm}^{3}\right) 1$ st day & $4,239,200 \pm 17,852$ & $3,036,200 \pm 16,953$ & 0.036 \\
\hline RBC (-/mm $\left.{ }^{3}\right) 3 \mathrm{rd}$ day & $4,091,000 \pm 17,982$ & $3,192,000 \pm 16,872$ & 0.058 \\
\hline Paired comparation & 0.635 & 0.354 & \\
\hline
\end{tabular}

WBC, white blood cells count; RBC, red blood cell count. P-values were determined using the Student's t-test. Significant P-values $(\mathrm{P}<0.05)$ are indicated in bold print.

in the control group $(\mathrm{P}=0.459)$. The analyzed cohort was homogenous and did not show any significant differences regarding weight $(\mathrm{P}=0.183)$. Duration of $\mathrm{PROM}$ was more than $72 \mathrm{~h}$ in the study group compared with control group $(15.00 \pm 2.83 \mathrm{~h})(\mathrm{P}=0.001)$ (Table I). In addition, we found a statistical difference in head circumference (HC) in the study group $(32.63 \pm 3.48 \mathrm{~cm})$ when compared to the control group $(35.00 \pm 2.96 \mathrm{~cm})(\mathrm{P}=0.030)$.

Hematological parameters and inflammatory markers. The laboratory studies including hematological parameters and inflammatory markers (CRP, IL-6, TNF- $\alpha$, ENA 78, IL-10) the oxygen need $\mathrm{FiO}_{2}$, and Astrup were measured in the delivery room, or immediately after admission into the NICU in the first hour.

In the first determination of Astrup parameters, there were no differences $(\mathrm{P}=0.880)$ in the $\mathrm{pH}$ values in both groups. All the parameters were within normal range. The $\mathrm{pH}$ value improved significantly $(\mathrm{P}=0.001)$ on the third day in the study group ( $\mathrm{pH}=7.32 \pm 0.058)$ (Table II).
The mean of the oxygen saturation in the 1st day was significantly lower in the study group $(81.26 \pm 11.94 \%)$, compared to control group $(89.29 \pm 16.45 \%)(\mathrm{P}=0.004)$. On the third day, the oxygenation parameters were improved in both groups $(\mathrm{P}=0.192)$ (Table II).

At the first evaluation of the hematological studies, we noted that the white blood cell count (WBC) was significantly higher in the study group vs. the control group $\left(14,992 \pm 6,398 / \mathrm{mm}^{3}\right.$ vs. $\left.11,871 \pm 3,875 / \mathrm{mm}^{3}\right)(\mathrm{P}=0.044)$. In the study group, WBC and plaquettes had a significant decreased value in the 3 rd day of life compared with the 1st day $(\mathrm{P}<0.001$ for $\mathrm{WBC}$ and $\mathrm{P}=0.010$ for plaquettes) (Table II).

Red blood cells (RBC) had a significant higher value on the 1st day in the study group vs. the control group $\left(4,239,200 \pm 17,852 / \mathrm{mm}^{3}\right.$ vs. $\left.3,036,200 \pm 16,953 / \mathrm{mm}^{3}\right)$ $(\mathrm{P}=0.036)$.

All the plasmatic values of CRP, IL- 6 , TNF- $\alpha$ and ENA-78 on the 1st day were higher in the newborns from mothers with PROM (study group), compared to the control group, but the difference was not significant for all of them just for IL-10 and 
Table III. Dynamics of the cytokines and CRP.

\begin{tabular}{|c|c|c|c|}
\hline Parameters & Study group $(n=36)$ & Control group $(n=46)$ & P-value \\
\hline CRP (mg\%) & $0.83 \pm 0.85$ & $0.60 \pm 0.00$ & $0.122^{\mathrm{a}}$ \\
\hline TNF- $\alpha(\mathrm{pg} / \mathrm{ml}) 1 \mathrm{st}$ day & $14.68 \pm 28.11$ & $8.99 \pm 6.81$ & $0.207^{\mathrm{a}}$ \\
\hline TNF- $\alpha(\mathrm{pg} / \mathrm{ml}) 3 \mathrm{rd}$ day & $10.08 \pm 14.61$ & $3.25 \pm 1.91$ & $0.419^{\mathrm{a}}$ \\
\hline P-value & $0.253^{\mathrm{b}}$ & $0.180^{\mathrm{b}}$ & \\
\hline ENA-78 (pg/ml) 1st day & $1,317.98 \pm 1,053.56$ & $1,172.26 \pm 1,095.99$ & $\mathbf{0 . 0 3 7}{ }^{\mathrm{a}}$ \\
\hline ENA-78 (pg/ml) 3rd day & $812.33 \pm 901.50$ & $592.70 \pm 312.97$ & $0.893^{\mathrm{a}}$ \\
\hline P-value & $0.049^{\mathrm{b}}$ & $0.182^{\mathrm{b}}$ & \\
\hline IL-10 (pg/ml) 1st day & $55.463 \pm 43.59$ & $42.41 \pm 58.08$ & $0.020^{\mathrm{a}}$ \\
\hline IL-10 (pg/ml) 3rd day & $25.97 \pm 18.19$ & 111.10 & $0.092^{\mathrm{a}}$ \\
\hline P-value & $<0.001^{\text {b }}$ & $0.317^{\mathrm{b}}$ & \\
\hline IL-6 (pg/ml) 1st day & $153.67 \pm 207.80$ & $114.23 \pm 156.01$ & $0.298^{\mathrm{a}}$ \\
\hline IL-6 (pg/ml) 3rd day & $46.49 \pm 87.96$ & $84.00 \pm 105.36$ & $0.508^{a}$ \\
\hline P-value & $<0.001^{\mathrm{b}}$ & $>0.999^{\mathrm{b}}$ & \\
\hline
\end{tabular}

CRP, C-reactive protein; TNF- $\alpha$, tumor necrosis factor- $\alpha$; ENA 78, neutrophil activating peptide 78; IL, interleukin. Data are presented as the mean \pm SD. ${ }^{a}$ Kruskal-Wallis test; ${ }^{b}$ Wilcoxon signed rank test. Significant $\mathrm{P}$-values $(\mathrm{P}<0.05)$ are indicated in bold print.

ENA-78. The dynamics in the first and 3rd day of life for the cytokines were different between the study group and control group (Table III).

IL-6, during the 1st day of life in the study group had the plasmatic value of $153.67 \pm 207.80 \mathrm{pg} / \mathrm{ml}$, higher, when compared with the control group $(114.23 \pm 156.01 \mathrm{pg} / \mathrm{ml})$. Under antibiotic treatment, the value was decreased significantly in the $3 \mathrm{rd}$ day of life $(46.49 \pm 87.96 \mathrm{pg} / \mathrm{ml})(\mathrm{P}<0.001)$ in the study group.

TNF- $\alpha$ was higher in the first day in the study and control groups. At the second evaluation, the plasmatic value was lower in both groups with no statistical differences found (Table III).

In our study, ENA-78 was significantly higher in the 1st day in the study group compared with the control group $(1,317.98 \pm 1,053.56 \mathrm{pg} / \mathrm{ml}$ vs. $1,172.26 \pm 1,095.99 \mathrm{pg} / \mathrm{ml})$ $(\mathrm{P}=0.037)$ and in the study group there was a significant decrease (to $812.33 \pm 901.50 \mathrm{pg} / \mathrm{ml}$ ) on the $3 \mathrm{rd}$ day of life $(\mathrm{P}=0.049)$. On the 3rd day of life we found no significant difference between the two groups (0.893) (Table III).

We evaluated the dynamics of the cytokines in the group of survivors, compared to the deceased neonatal group. In the survival group, the decrease in ENA-78 $(\mathrm{P}=0.026)$ and IL-10 $(\mathrm{P}<0.001)$ was significant from the 1 st day to the 3rd day. The blood level of ENA-78 was significant higher $(1,266.60 \pm 1,099.16 \mathrm{pg} / \mathrm{ml})$ in the survival group vs. the deceased group $336.00 \pm 462.50 \mathrm{pg} / \mathrm{ml}(\mathrm{P}=0.037)$ on the 1st day. ENA-78 was significantly lower on the 3rd day of life $(737.19 \pm 781.39 \mathrm{pg} / \mathrm{ml})(\mathrm{P}=0.026)$ in the survival group (Table IV). Also, the dynamics of ENA-78 was significantly different in the deceased group vs. the survival group, with the values of ENA 78 higher on the 3rd day vs. the 1st day in the deceased group.

IL-6 also exhibited a significant decrease on the 3rd day of life in the survival group $(\mathrm{P}<0.001)$ (Table IV).

IL-10, also known as the marker of the anti-inflammatory response, presented significantly higher values with statistical differences on the 1st day of life vs. the 3rd day, in the study group $(55.463 \pm 43.59 \mathrm{pg} / \mathrm{ml}$ vs. $25.97 \pm 18.19 \mathrm{pg} / \mathrm{ml})(\mathrm{P}<0.001)$. But the dynamics were significantly different in infants who had already developed morbidities; the values on the 1st day were higher compared to the 3rd day. In the study group, the plasmatic value of IL-10 on the first day decreased significantly compared to the value on the 3 rd day $(55.463 \pm 43.59$ to $25.97 \pm 18.19 \mathrm{pg} / \mathrm{ml})(\mathrm{P}<0.001)$ (Table III).

Furthermore, we aimed to correlate the plasmatic value of the cytokines with the major morbidities in the first week of life: sepsis, RDS, CH, and NEC (Table V). We observed a higher plasmatic value of TNF- $\alpha$ in the neonatal cases with cerebral hemorrhage $(36.05 \pm 49.53 \mathrm{pg} / \mathrm{ml})$ and sepsis $(13.18 \pm 25.98 \mathrm{pg} / \mathrm{ml})$ on the 1st day of life. The highest value of ENA-78 was found in newborns with cerebral hemorrhage $(1,540.70 \pm 1,295.87 \mathrm{pg} / \mathrm{ml})$ and NEC $(1,420.95 \pm 1,373.88 \mathrm{pg} / \mathrm{ml})$ on the 1 st day (Table V). IL-10 had the highest value $(63.06 \pm 37.22 \mathrm{pg} / \mathrm{ml})$ in newborns with sepsis on the 1st day of life. IL-6 had its highest value $(219.27 \pm 227.42 \mathrm{pg} / \mathrm{ml})$ on the 1 st day in the sepsis group and the highest value on the 3rd day was in the NEC group $(215.83 \pm 256.47 \mathrm{pg} / \mathrm{ml})($ Table V).

No correlation was found between PROM duration and any cytokine from the study in the 1 st day of life $(\mathrm{P}=0.36)$.

We found no correlation of these parameters with infant mortality $(\mathrm{P}=0.57)$.

\section{Discussion}

In our study, preterm newborns with premature rupture of the membranes (PROM) were successfully assessed.

In the event of PROM, a fetus can develop an inflammatory response following exposure to microorganisms such as bacteria from the vaginal flora, fungi, or protozoans. This process can affect an organ, for example the pulmonary inflammation caused by meconial aspiration, or cause a systemic process caused by the increase in inflammatory markers in the circulation (4).

Fetuses in pregnancies with PROM are prone to inflammation or intra-amniotic infection. There are multiple studies that 
Table IV. Correlation between cytokines and survival among the study population.

\begin{tabular}{lccc}
\hline Parameters & Survival group & Deceased group & P-value \\
\hline CRP $(\mathrm{mg} \%)$ & $0.78 \pm 0.76$ & $0.60 \pm 0.00$ & $7.97 \pm 7.34$ \\
TNF- $\alpha(\mathrm{pg} / \mathrm{ml})$ 1st day & $13.51 \pm 25.01$ & $4.70 \pm 4.76$ & 0.461 \\
TNF- $\alpha(\mathrm{pg} / \mathrm{ml})$ 3rd day & $10.16 \pm 14.80$ & $0.655^{\mathrm{a}}$ & 0.387 \\
P-value & $0.124^{\mathrm{a}}$ & $336.00 \pm 462.50$ \\
ENA 78 (pg/ml) 1st day & $1,266.60 \pm 1,099.16$ & $1,518.27 \pm 1,730.64$ \\
ENA 78 (pg/ml) 3rd day & $737.19 \pm 781.39$ & $0.109^{\mathrm{a}}$ \\
P-value & $\mathbf{0 . 0 2 6}^{\mathrm{a}}$ & $84.15 \pm 92.70$ \\
IL-10 (pg/ml) 1st day & $49.15 \pm 41.68$ & $25.25 \pm 13.50$ \\
IL-10 (pg/ml) 3rd day & $28.51 \pm 23.41$ & $0.180^{\mathrm{a}}$ \\
P-value & $<\mathbf{0 . 0 0 1}^{\mathrm{a}}$ & $82.85 \pm 68.73$ \\
IL-6 (pg/ml) 1st day & $147.69 \pm 200.60$ & $188.60 \pm 279.61$ \\
IL-6 (pg/ml) 3rd day & $36.16 \pm 41.35$ & $>0.999^{\mathrm{a}}$ \\
P-value & $<\mathbf{0 . 0 0 1}^{\mathrm{a}}$ & 0.312
\end{tabular}

CRP, C-reactive protein; TNF- $\alpha$, tumor necrosis factor- $\alpha$; ENA 78, neutrophil activating peptide 78; IL, interleukin. P-values were determined using the Kruskal-Wallis test. Data are presented as the mean \pm SD. ${ }^{a}$ Wilcoxon signed rank test. Significant $\mathrm{P}$-values $(\mathrm{P}<0.05)$ are indicated in bold print.

Table V. Association between cytokines and neonatal morbidities.

\begin{tabular}{|c|c|c|c|c|c|}
\hline Neonatal pathology & RDS & Cerebral hemorrhage & Sepsis & NEC & P-value \\
\hline CRP (mg/dl) & $0.60 \pm 0.00$ & $0.90 \pm 0.73$ & $0.94 \pm 1.23$ & $0.72 \pm 0.40$ & 0.743 \\
\hline TNF- $\alpha(\mathrm{pg} / \mathrm{ml}) 1 \mathrm{st}$ day & $1.87 \pm 0.61$ & $36.05 \pm 49.53$ & $13.18 \pm 25.98$ & $8.96 \pm 14.06$ & 0.207 \\
\hline $\mathrm{TNF}-\alpha(\mathrm{pg} / \mathrm{ml}) 3 \mathrm{rd}$ day & $4.73 \pm 4.73$ & $14.35 \pm 20.09$ & $7.93 \pm 13.79$ & $11.82 \pm 14.887$ & 0.389 \\
\hline ENA (pg/ml) 1st day & $387.80 \pm 550.49$ & $1,540.70 \pm 1,295.87$ & $833.59 \pm 485.84$ & $1,420.95 \pm 1,373.88$ & 0.243 \\
\hline ENA (pg/ml) 3rd day & $1,303.13 \pm 1,894.33$ & $611.65 \pm 270.99$ & $601.88 \pm 676.83$ & $1,035.48 \pm 1042.32$ & 0.566 \\
\hline IL-10 (pg/ml) 1st day & $40.27 \pm 9.04$ & $50.80 \pm 67.20$ & $63.06 \pm 37.22$ & $52.73 \pm 44.86$ & 0.312 \\
\hline IL-10 (pg/ml) 3rd day & $19.67 \pm 13.59$ & $24.60 \pm 27.31$ & $28.19 \pm 14.76$ & $25.63 \pm 19.36$ & 0.388 \\
\hline IL-6 (pg/ml) 1st day & $113.84 \pm 172.72$ & $153.70 \pm 288.45$ & $219.27 \pm 227.42$ & $77.03 \pm 44.32$ & 0.451 \\
\hline IL-6 (pg/ml) 3rd day & $39.85 \pm 43.14$ & $33.08 \pm 39.23$ & $18.60 \pm 15.31$ & $215.83 \pm 256.47$ & 0.166 \\
\hline
\end{tabular}

RDS, respiratory distress syndrome; NEC, necrotizing enterocolitis; CRP, C-reactive protein; TNF- $\alpha$, tumor necrosis factor- $\alpha$; ENA 78, neutrophil activating peptide 78 ; IL, interleukin. Data are presented as the mean $\pm \mathrm{SD}$.

have evaluated this process, but the exact mechanism of the development of these inflammatory states is not yet completely understood (1).

In the study group, which was affected by PROM, the newborns presented with a lower $\mathrm{pH}$ and $\mathrm{pO}_{2}$, but following antibiotic treatment, oxygen therapy or respiratory support, these values were improved on the third day of life. Romero et al founded no significant differences in the $\mathrm{pH}$ value in premature babies with fetal inflammatory response syndrome (FIRS) compared with controls (10).

We assessed the hematopoietic system in our study and control group. Neutrophils are involved in the host response in the context of PROM and FIRS. In the study group, we found significantly higher levels of WBC $14,992 \pm 6,398 / \mathrm{mm}^{3}$ vs. $11,871 \pm 3,875 / \mathrm{mm}^{3}$. The mechanism responsible for neutrophil stimulation is attributed to the secretion of G-CSF, which is a cytokine responsible for the activation of neutrophils in inflammatory response. This has also been observed in fetuses with FIRS (11).

We also observed a significant decrease in thrombocytes in the study group from the first to the third day of life. The thrombocyte count presented differences between the study and control group on the third day of life, barely missing the threshold for statistical difference. There is no clear explanation for this difference, but it does seem like the hematopoietic system plays a significant role in the pathology of FIRS.

The WBC showed significantly increased numbers on the 1st day of life in the study group. These changes sustain the FIRS diagnostic in the study group. In addition, Dulay et al in their study assessing inflammation-associated preterm birth and in the absence of hypoxia observed the elevations in nucleated red blood cells (NRBCs) in the early neonatal period and considered this fact as a possibility of a direct response of exposure to inflammatory mediators in utero (12). 
The inflammatory response to infection involves both a pro- and an anti-inflammatory response (4,13-15). In our study, IL-6 had higher plasmatic values in the study group compared to the control group. Romero et al report that a value of IL-6 over $11 \mathrm{pg} / \mathrm{ml}$ in fetuses with FIRS leads to an earlier birth, than those with lower values (10).

In our study, we selected fetuses from pregnancies with PROM and we analyzed the same parameters. The originality of our research consists of the 3rd day dynamics of these parameters in correlation with the neonatal outcome.

Depending on the balance of the cytokines, the newborn can either present with an inflammatory syndrome, FIRS, with neonatal sepsis or with another morbidity. In our study we compared the levels of the abovementioned cytokines in order to correlate them with a specific complication [sepsis, respiratory distress syndrome (RDS), necrotizing enterocolitis (NEC) and cerebral hemorrhage].

We found an increase value of IL-6 $(147.69 \pm 200.60 \mathrm{pg} / \mathrm{ml})$ in the survival group compared with the deceased group $(82.85 \pm 68.73 \mathrm{pg} / \mathrm{ml})$ in the $1 \mathrm{st}$ day. A value over $11.6 \mathrm{pg} / \mathrm{ml}$ was associated with a higher mortality rate $(77.8 \%$ vs. $29 \%)$ $(\mathrm{P}<0.001)$, pending on the presence of FIRS, as described by Gomez et al (4). The significant decrease in the third day of live of the IL- 6 value can be considered a response to the disease-specific management and use of wide spectrum antibiotics. IL-6 is involved in perinatal morbidity such as RDS, NEC, cerebral hemorrhage and sepsis (16).

The relationship between the infection, inflammation and respiratory complications is an important research topic in neonatology.

We noted that ENA-78 has not been frequently evaluated as a parameter in FIRS and newborn. We consider that our study contributes to the understanding of FIRS and how it may influence neonatal morbidity. In the present study, the highest value of ENA-78 was observed in newborns which developed cerebral hemorrhage $(1,540.70 \pm 1,295.87 \mathrm{pg} / \mathrm{ml})$ and NEC $(1,420.95 \pm 1,373.88 \mathrm{pg} / \mathrm{ml})$.

FIRS is a risk factor for necrotizing enterocolitis $(17,18)$. Considerable evidence now sustains that fetal inflammation and often infections could be related to fetal/neonatal neuro-inflammation, brain injury or neurodevelopmental disorders, including mental illnesses $(19,20)$. The highest value found in cerebral hemorrhage sustains this observation once again.

The mechanism of brain injury in FIRS is complex. Exposure to in utero inflammation initiates a cascade of the fetal immune response, where pro-inflammatory cytokines can cause direct injury to oligodendrocytes and neurons by activating microglia (21).

The most vulnerable structures are pre-myelinating oligo-dendrocytes (22).

The clinical significance of the pro- and anti-inflammatory balance in FIRS is mainly to determine an algorithm for management of these conditions. In our study, IL-10 (as the anti-inflammatory component of fetal inflammatory response), presented a significant difference between the study and control groups, a difference which maintained its significance on the third day of life.

We considered that the balance between the pro- and anti-inflammatory cytokines may play an important role in the prevention of neonatal morbidities such as cerebral hemorrhage or NEC.

We found only a few studies to compare the dynamics of pro-inflammatory cytokines and IL-10 an IL-8. In one of the study, Beresford and Shaw sustain the important role of IL-8 in the inflammatory response to respiratory injury, and also the difficulty in detecting counter-regulatory cytokines such as IL-10 in the bronchial lavage fluid (23).

Furthermore, IL-10 deficiency may be a factor in the etiology of bronchopulmonary dysplasia (BPD). Harris et al investigated the cytokine secretion in critically ill infants with bacterial sepsis, NEC, or sepsis syndrome and documented increased values of IL-10 and ENA-78 in newborns which developed NEC, compared to those who developed bacterial sepsis (24). Ng et al consider IL-10 as an early diagnostic marker of late onset bacterial infection in preterm infants (25).

To our knowledge, there are no studies related to the dynamics of TNF- $\alpha$ and ENA-78 in correlation with neonatal morbidity and mortality. We analyzed the dynamics of cytokines comparing the survivor and the deceased groups. IL-6, ENA-78, TNF- $\alpha$, IL-10 had their own contribution depending on the day of life.

Increased values on the first day of life could be considered a risk factor for an increased neonatal morbidity, especially for premature or growth-restricted babies $(26,27)$. In our research, ENA-78 had significantly higher values in the survival group compared to the pattern of TNF- $\alpha$ value. However, the augmentation of the inflammatory process was revealed by the increase in ENA-78 on the third day of life, in cases complicated with neonatal death.

The decrease in the anti-inflammatory pattern for ENA-78, IL-10, and IL-6 on the third day of life was significantly encountered in the survival group.

The concomitant decrease of ENA-78 and IL-10 during the third day of life could suggest the evolution through the culmination of the inflammatory process.

FIRS remains an important issue when we want to refer to the morbidity and prognosis of premature babies, newborns or babies with intrauterine growth restriction, with premature rupture of the membranes $(28,29)$.

This study has its limitations. The small number of cases and the lack of correlation with pathological changes in umbilical cord or placenta are important, but we consider that the study of immunological response in preterm can offer possibilities to better understand the prognosis of these infants. Studies with more case numbers and more parameters could provide more clarity towards managing these conditions more appropriately.

In conclusion, the appearance of a certain FIRS-associated disease seems to be influenced by the balance between pro-inflammatory and anti-inflammatory cytokines. A concomitant decrease in both ENA-78 and IL-10, was associated with a better survival of the neonates, even though this association failed to reach significance.

\section{Acknowledgements}

We appreciate the efforts of our team in conducting and elaborating the research and special thanks to Rodica Rahaian for processing the laboratory data. 


\section{Funding}

This research was supported by grant funding CNCSIS (Biological markers: TNF- $\alpha$, Il-6, Il-10, ENA-78 and Toll-like receptors: TLR-2 and TLR-4-the prognostic and diagnostic value in newborns with neonatal sepsis, contract no. 22).

\section{Availability of data and materials}

The datasets used and/or analyzed during the current study are available from the corresponding author on reasonable request.

\section{Authors' contributions}

GCZ contributed to the study design, result interpretation, and manuscript writing process. TD interpreted the results and conducted the statistical analysis. CC interpreted the results and pathologic neonatal condition. DM recruited the pregnant women for the study and performed the data collection. AZ, FZ, and MGH were involved in the literature research and manuscript writing process. MM contributed to the study design and the result interpretation. All authors read and approved the manuscript and agree to be accountable for all aspects of the research in ensuring that the accuracy or integrity of any part of the work are appropriately investigated and resolved.

\section{Ethics approval and consent to participate}

In obtaining inform consent and conducting the evaluations, the study adhered to principles outlined in the Declaration of Helsinki on experimentation involving human subjects. We obtained ethics approval from the Ethics Committee of the County Emergency Hospital Cluj-Napoca, Romania (no 140/25.06. 2017).

\section{Patient consent for publication}

Not applicable.

\section{Competing interests}

The authors declare that they have no competing interests.

\section{Authors' information}

Author Alexandru Zaharie is a medical resident, Department of Radiation Oncology, Medical University of Vienna, Austria. Author Flaviu Zaharie is a student at 'Iuliu Haţieganu' University of Medicine and Pharmacy, 400000Cluj-Napoca, Romania. The ORCID numbers are as follows: Gabriela C. Zaharie, https://orcid.org/0000-0002-2722-8166; Tudor Drugan, https://orcid.org/0000-0003-0097-262X; CarmenCrivii, https://orcid.org/0000-0001-5275-5753; Daniel Muresan, https://orcid.org/0000-0002-7744-0501; AlexandruZaharie, https://orcid.org/0000-0002-8697-9058; Monica G. Hășmășanu, https://orcid.org/0000-0002-1279-6654; Melinda Matyas, https://orcid.org/0000-0003-0677-5846.

\section{References}

1. Jung E, Romero R, Yeo L, Diaz-Primera R, Marin-Concha J, Para R, Lopez AM, Pacora P, Gomez-Lopez N, Yoon BH, et al: The fetal inflammatory response syndrome: The origins of a concept, pathophysiology, diagnosis, and obstetrical implications. Semin Fetal Neonatal Med 25: 101146, 2020.

2. Tang Q, Zhang L, Li H and Shao Y: The fetal inflammation response syndrome and adverse neonatal outcomes: A meta-analysis. J Matern Fetal Neonatal Med 1-13, Dec 18, 2019 (Epub ahead of print).

3. Thilaganathan B, Carroll SG, Plachouras N, Makrydimas G and Nicolaides KH: Fetal immunological and haematological changes in intrauterine infection. Br J Obstet Gynaecol 101: 418-421, 1994.

4. Gomez R, Romero R, Ghezzi F, Yoon BH, Mazor M and Berry SM: The fetal inflammatory response syndrome. Am J Obstet Gynecol 179: 194-202, 1998.

5. Stampalija T, Romero R, Korzeniewski SJ, Chaemsaithong P, Miranda J, Yeo L, Dong Z, Hassan SS and Chaiworapongsa T: Soluble ST2 in the fetal inflammatory response syndrome: In vivo evidence of activation of the anti-inflammatory limb of the immune response. J Matern Fetal Neonatal Med 26: 1384-1393, 2013.

6. Pool C: The vermont oxford network and care of premature infants https://www.wtamu.edu/webres/File/Academics/Graduate\%20 School/Honors/Pool\%20Capstone\%20Internship.pdf).

7. McGovern M, Giannoni E, Kuester H, Turner MA, van den Hoogen A, Bliss JM, Koenig JM, Keij FM, Mazela J, Finnegan R, et al: Challenges in developing a consensus definition of neonatal sepsis. Pediatr Res 88: 14-26, 2020.

8. National Healthcare Safety Network (NHSN): CDC/NHSN Surveillance Definitions for Specific Types of Infections, 2021.

9. de Vries LS and Heep A: Cerebral hemorrhage in newborns. In: Neonatology. Springer International Publishing, pp2201-2224, 2018.

10. Romero R, Soto E, Berry SM, Hassan SS, Kusanovic JP, Yoon BH, Edwin S, Mazor M and Chaiworapongsa T: Blood pH and gases in fetuses in preterm labor with and without systemic inflammatory response syndrome. J Matern Fetal Neonatal Med 25: 1160-1170, 2012.

11. Chaiworapongsa T, Romero R, Berry SM, Hassan SS, Yoon BH, Edwin S and Mazor M: The role of granulocyte colony-stimulating factor in the neutrophilia observed in the fetal inflammatory response syndromegsa. J Perinat Med 39: 653-666, 2011.

12. Dulay AT, Buhimschi IA, Zhao G, Luo G, Abdel-Razeq S, Cackovic M, Rosenberg VA, Pettker CM, Thung SF, Bahtiyar MO, et al: Nucleated red blood cells are a direct response to mediators of inflammation in newborns with early-onset neonatal sepsis. Am J Obstet Gynecol 198: 426.e1-e9, 2008.

13. Hotchkiss RS and Karl IE: The pathophysiology and treatment of sepsis. N Engl J Med 348: 138-150, 2003.

14. Hotchkiss RS, Moldawer LL, Opal SM, Reinhart K, Turnbull IR and Vincent JL: Sepsis and septic shock. Nat Rev Dis Primers 2: $16045,2016$.

15. Hotchkiss RS, Monneret G and Payen D: Sepsis-induced immunosuppression: From cellular dysfunctions to immunotherapy. Nat Rev Immunol 13: 862-874, 2013.

16. Ferber A, Minior VK, Bornstein E and Divon MY: Fetal 'nonreassuring status' is associated with elevation of nucleated red blood cell counts and interleukin-6. Am J Obstet Gynecol 192: 1427-1429, 2005.

17. Been JV,Lievense S,Zimmermann LJ,Kramer BW and Wolfs TG: Chorioamnionitis as a risk factor for necrotizing enterocolitis: A systematic review and meta-analysis. J Pediatr 162: 236-242.e2, 2013.

18. Yan X, Managlia E, Tan XD and De Plaen IG: Prenatal inflammation impairs intestinal microvascular development through a TNF-dependent mechanism and predisposes newborn mice to necrotizing enterocolitis. Am J Physiol Liver Physiol 317: G57-G66, 2019.

19. Al-Haddad BJS, Oler E, Armistead B, Elsayed NA, Weinberger DR, Bernier R, Burd I, Kapur R, Jacobsson B Wang C, et al: The fetal origins of mental illness. Am J Obstet Gynecol 221: 549-562, 2019.

20. Murphy DJ, Sellers S, MacKenzie IZ, Yudkin PL and Johnson AM: Case-control study of antenatal and intrapartum risk factors for cerebral palsy in very preterm singleton babies. Lancet 346: 1449-1454, 1995. 
21. Matyas M, Hasmasanu MG and Zaharie G: Antioxidant capacity of preterm neonates assessed by hydrogen donor value. Medicina (Kaunas) 55: 720, 2019.

22. Yap V and Perlman JM: Mechanisms of brain injury in newborn infants associated with the fetal inflammatory response syndrome. Semin Fetal Neonatal Med 25: 101110, 2020.

23. Beresford MW and Shaw NJ: Detectable interleukin-10 and interleukin-8 in bronchoalveolar lavage fluid from preterm infants ventilated for respiratory distress syndrome. Early Hum Dev 58: 69-70, 2000.

24. Harris MC, D'Angio CT, Gallagher PR, Kaufman D, Evans J and Kilpatrick L: Cytokine elaboration in critically ill infants with bacterial sepsis, necrotizing entercolitis, or sepsis syndrome: Correlation with clinical parameters of inflammation and mortality. J Pediatr 147: 462-468, 2005.

25. Ng PC, Li K, Wong RP, Chui K, Wong E, Li G and Fok TF Proinflammatory and anti-inflammatory cytokine responses in preterm infants with systemic infections. Arch Dis Child Fetal Neonatal Ed 88: F209-F213, 2003.

26. Turcan N, Bohiltea RE, Ionita-Radu F, Furtunescu F, Navolan D, Berceanu C, Nemescu D and Cirstoiu MM: Unfavorable influence of prematurity on the neonatal prognostic of small for gestational age fetuses. Exp Ther Med 20: 2415-2422, 2020.
27. Bohiltea R, Furtunescu F, Turcan N: Prematurity and intrauterine growth restriction: Comparative analysis of incidence and short-term complication. Proceedings of SOGR 2018. In: Proceedings of the 17th National Congress of The Romanian Society of Obstetrics and Gynecology 2018, pp708-712, 2019.

28. Hăşmăşanu MG, Bolboacă SD, Drugan TC, Matyas M and Zaharie GC: Parental factors associated with intrauterine growth restriction. Srp Arh Celok Lek 143: 701-706, 2015.

29. Preda A, Caracostea G, Ona D, Zaharie G and Stamatian F: Association between maternal/newborn genetic variants, placental pathology and spontaneous preterm birth risk: A Romanian population-based study. J Matern Fetal Neonatal Med 33: 1171-1177, 2020. 